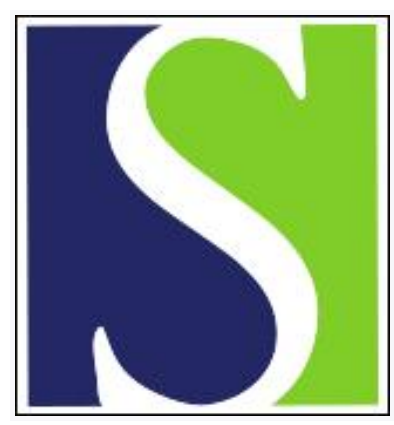

Scand J Work Environ Health 1998;24(5):392-397

https://doi.org/10.5271/sjweh.360

Issue date: Oct 1998

Anthophyllite exposure and endemic pleural plaques in Kumamoto, Japan

by Hiraoka T, Ohkura M, Morinaga K, Kohyama N, Shimazu K, Ando M

Key terms: anthophyllite; asbestos exposure; environmental exposure; mass screening; pleural plaque

This article in PubMed: www.ncbi.nlm.nih.gov/pubmed/9869311

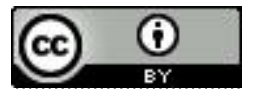




\title{
Anthophyllite exposure and endemic pleural plaques in Kumamoto, Japan
}

\author{
by Takesuke Hiraoka, MD, ${ }^{1}$ Masanori Ohkura, MD, ${ }^{1}$ Kenji Morinaga, MD, ${ }^{2}$ Norihiko Kohyama, PhD, ${ }^{3}$ \\ Kazuyoshi Shimazu, MD, ${ }^{1}$ Masayuki Ando, MD4
}

\begin{abstract}
Hiraoka T, Ohkura M, Morinaga K, Kohyama N, Shimazu K, Ando M. Anthophyllite exposure and endemic pleural plaques in Kumamoto, Japan. Scand J Work Environ Health 1998;24(5):392-397.

Objectives This study explored the high prevalence of pleural plaques in the town of Matsubase in Kumamoto, Japan.

Methods Small-size chest X-ray film was used for screening, and all persons with pleural plaques were confirmed by computed tomography (CT). The prevalence rate of pleural plaques in the 4 districts of Matsubase and its surrounding towns and cities were also examined. The age-adjusted mortality rate for lung cancer in this town was compared with that of its surrounding towns and cities.

Results Pleural plaques were found in 1357 persons ( 724 men and 633 women) among the inhabitants who were more than 20 years of age in Matsubase between 1988 and 1993. CT scans ascertained 938 cases with pleural plaques among the 1114 persons who participated. Thus at least $9.5 \%$ of the inhabitants over 20 years of age in this town had pleural plaques. The neighboring towns had a higher rate than the more distant towns. A large-scale opencast asbestos mine and mill had been in operation in Matsubase between 1883 and 1970. Mineral analysis revealed anthophyllite fibers. Most of the plaques were found in persons who had never worked in the mine or mill.

Conclusions The high prevalence of pleural plaques in Matsubase was due to anthophyllite exposure, mainly environmental. No mesotheliomas were found, however. These findings agree with those from an earlier study from Finland.
\end{abstract}

Key terms anthophyllite, asbestos exposure, environmental exposure, mass screening, pleural plaques.

Pleural plaques can be regarded as a typical sign of asbestos fiber inhalation $(1-3)$. These fibers are mainly found in persons with occupational exposure. Kiviluoto (4), in 1960, described an endemic occurrence of pleural calcifications in subjects living near anthophyllite mines in Finland. Since this report, endemic plaques have been described from many parts of the world, such as Bulgaria (5), Czechoslovakia (6), Austria (7), Greece (8), Cyprus (9), and Corsica (10).

The Kumamoto prefecture is located on the island of Kyushu in Japan. Mass screening programs for lung can- cer in inhabitants over 40 years of age have been conducted in almost all towns in Kumamoto since 1986. In such a mass screening of Matsubase inhabitants, performed in 1988, the roentgenograms taken at the National Kumamoto-Minami Hospital showed a very high prevalence of pleural plaques. Matsubase had a population of 21689 in 1988, with 7500 inhabitants over the age of 40 years. In this age group, 357 people $(4.8 \%)$ had participated in the screening, and 148 of them $(41.5 \%)$ showed typical plaques $(11,12)$. Some asbestos mines and mills had existed earlier in the area. Since no occupational

1 National Kumamoto-Minami Hospital, Matsubase, Kumamoto, Japan.

Osaka Medical Center for Cancer and Cardiovascular Diseases, Osaka, Higashinari-Ku, Osaka, Japan.

National Institute of Industrial Health, Ministry of Labor, Kawasaki, Kanagawa, Japan.

First Department of Internal Medicine, Kumamoto University School of Medicine, Kumamoto, Japan.

Reprint requests to: Dr Takesuke Hiraoka, National Miyazaki Hospital, Kawaminami 889_1301, Miyazaki, Japan. [E-mail: hiraoka@miyazaki.hosp.go.jp] 
asbestos exposure could be determined, the pleural plaques were attributed to exposure to asbestos from these mines and mills. A special follow-up system was instituted for 5 years, from 1989 to 1993, to investigate the health of the inhabitants with pleural plaques.

\section{Subjects and methods}

\section{Subjects}

From 1988 to $1993,9832(81.2 \%)$ of the inhabitants over 20 years of age were investigated by chest X-ray (table 1). Pleural plaques were found in 1357 persons ( 724 men and 633 women). A computed-tomography (CT) scan was performed for 1114 of these cases (82.1\%), and pleural plaques were confirmed in 938 of the persons who had a scan $(84.2 \%)$. Thus there were 472 men and 466 women with plaques confirmed by CT scan.

\section{Radiological methods}

Small-size chest X-ray film $(100 \times 100 \mathrm{~mm})$ was used for the screening. The films were interpreted independently by 2 specialists and inspected by a $3 \mathrm{rd}$. The criteria of Askergren \& Szamosi (13) were used for the diag nosis of pleural plaques. Persons with pleural plaques were recalled for an interview, including an occupational history, and were offered a CT scan of the chest to verify the findings.

\section{Calculations}

The age-adjusted mortality rate from lung cancer in Matsubase was calculated from a comparison with the 1990 census figures.

The Matsubase area consists of the 4 districts of Matsubase, Toyofuku, Toyokawa, and Tohno. The prevalence of pleural plaques was calculated for these 4 districts. Former asbestos mine workers were also interviewed. Through the archives and interviews, the former asbestos mines and factories were located in the Matsubase area.

\section{Measurement of asbestos fibers}

The concentration of asbestos fibers in the air was determined at 2 points in and near a former asbestos factory site, and at 4 other points in Matsubase and 4 reference points (in a residential area, in a commercial area, along a highway in Kumamoto city, and in a rural area) in November 1990. Measurements were done by the Public Health Department of the Kumamoto Prefecture in accordance with the Manual of Asbestos Emission in the General Environment (14). The accumulated air volume, measured for 4 hours through a $0.8-\mu \mathrm{m}$ filter (Millipore $A A(47 \mathrm{~mm} \varnothing$ ) was $10 \mathrm{ml} / \mathrm{min}$. Asbestos fibers were counted with a phase contrast microscope, measuring
Table 1. Pleural plaques in 4 districts of Matsubasea (19881993).

\begin{tabular}{lcccc}
\hline $\begin{array}{l}\text { Name of } \\
\text { district }\end{array}$ & $\begin{array}{c}\text { Total } \\
\text { population } \\
(\mathrm{N})\end{array}$ & $\begin{array}{c}\text { Residents } \\
\text { > 20 years } \\
\text { of age (N) }\end{array}$ & $\begin{array}{c}\text { Residents } \\
\text { with plaques } \\
(\mathrm{N})\end{array}$ & $\begin{array}{c}\text { Plaque } \\
\text { prevalence } \\
(\%)\end{array}$ \\
\hline Matsubase & 2919 & 2183 & 123 & 5.6 \\
Toyofuku & 3317 & 2463 & 420 & 17.1 \\
Toyokawa & 2302 & 2141 & 91 & 4.3 \\
Tohno & 3570 & 3045 & 304 & 10.0 \\
\hline Total & 12108 & 9832 & 938 & 9.5 \\
\hline
\end{tabular}

a See figure 2 for its location.

fibers $\geq 5 \mu \mathrm{m}$ long. The asbestos ore was analyzed by one of the authors (NK) with an analytical transmission electron microscope equipped with an energy-dispersive $\mathrm{X}$ ray analyzer.

\section{Results}

Among the 938 Matsubase residents with pleural plaques $72 \%$ of the pleural plaques were calcified, and most were bilateral $(84.5 \%)$. The prevalence of pleural plaques increased dramatically with age (table 2 ). Persons aged 60 - 69 years had a prevalence rate which was more than 8 times higher than that of the persons who were $40-49$ years of age.

Formerly operating, but now closed mines and factories were found in the 2 districts of Toyofuku and Tohno (figures 1 and 2), and these districts also had the highest prevalence rate of pleural plaques (table 1). The cases were plotted on a map of Matsubase. Many were found near the former mines and mills, especially around Niregi, where 1 mine and the largest mill were located (figure 2). This mill had used ore from Uchida, formerly an opencast mine, which is now covered by soil.

The prevalence of pleural plaques was also investigated in the towns surrounding Matsubase (figure 1). The

Table 2. Age and gender distribution of the cases with pleural plaques.

\begin{tabular}{lcrrrr}
\hline $\begin{array}{l}\text { Age } \\
\text { (years) }\end{array}$ & $\begin{array}{c}\text { Number } \\
\text { of } \\
\text { persons } \\
\text { examined }\end{array}$ & Men & Women $\begin{array}{c}\text { Men and } \\
\text { women } \\
\text { combined }\end{array}$ \\
\cline { 3 - 6 } & & \multicolumn{4}{c}{ Pleural plaques } \\
\hline $20-39$ & 1671 & 2 & 4 & 6 & 0.4 \\
$40-49$ & 1576 & 27 & 12 & 39 & 2.5 \\
$50-59$ & 1714 & 98 & 84 & 182 & 10.6 \\
$60-69$ & 2601 & 175 & 154 & 329 & 12.6 \\
$\geq 70$ & 2279 & 170 & 212 & 382 & 16.8 \\
\hline Total & 9832 & 472 & 466 & 938 & 9.5 \\
\hline
\end{tabular}

a Percentage of persons examined. 

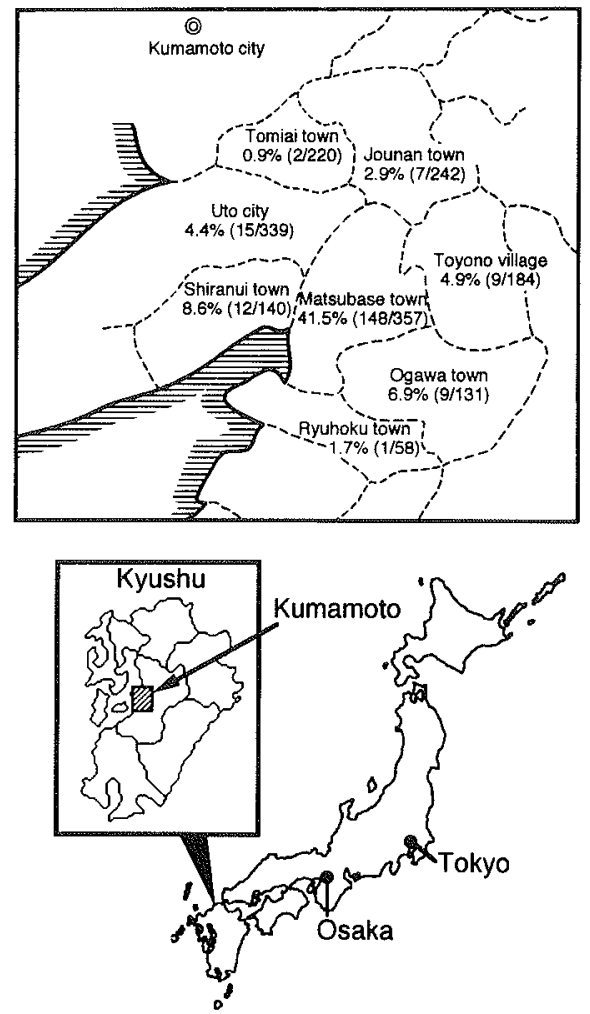

Figure 1. Geographic prevalence of pleural plaques in Matsubase and its surrounding towns and villages.

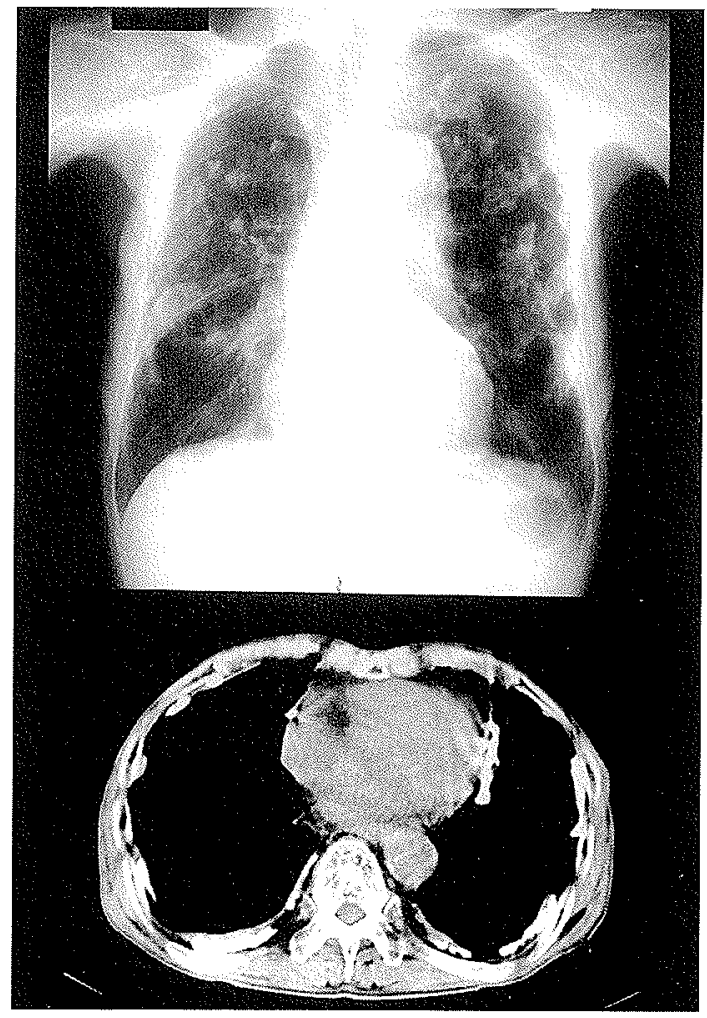

Figure 3. An 83-year-old man with occupational exposure to asbestos for 6 years. His chest-ray film reveals bilateral calcified plaques of the costal pleura, diaphragm, and pericardium.

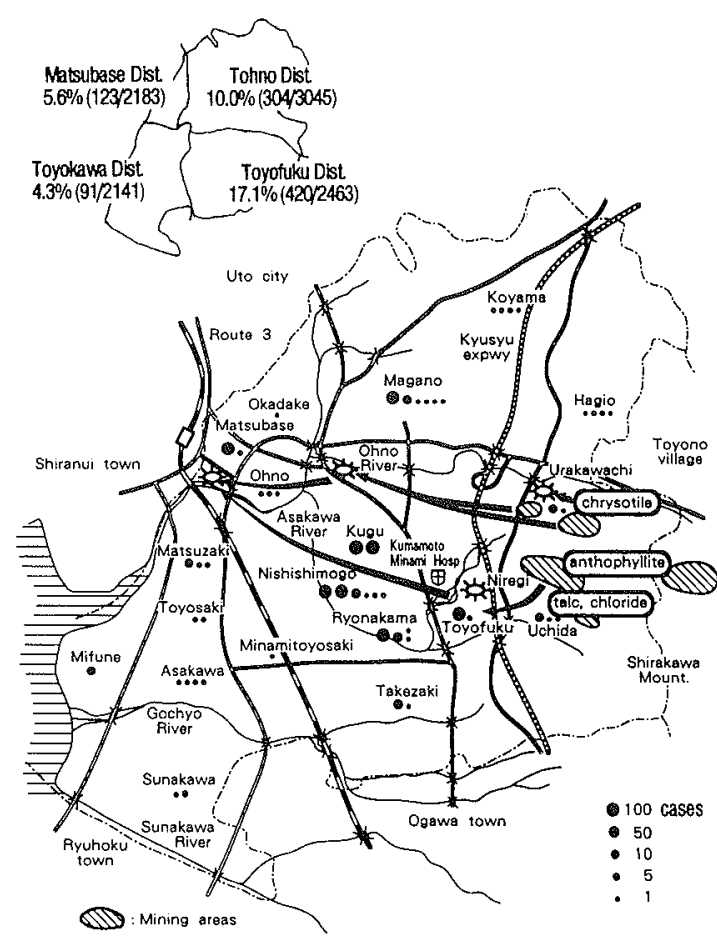

$\mathrm{I}_{1 \mathrm{~km}}$

Figure 2. Geographic distribution of inhabitants with pleural plaques in 4 districts of Matsubase.

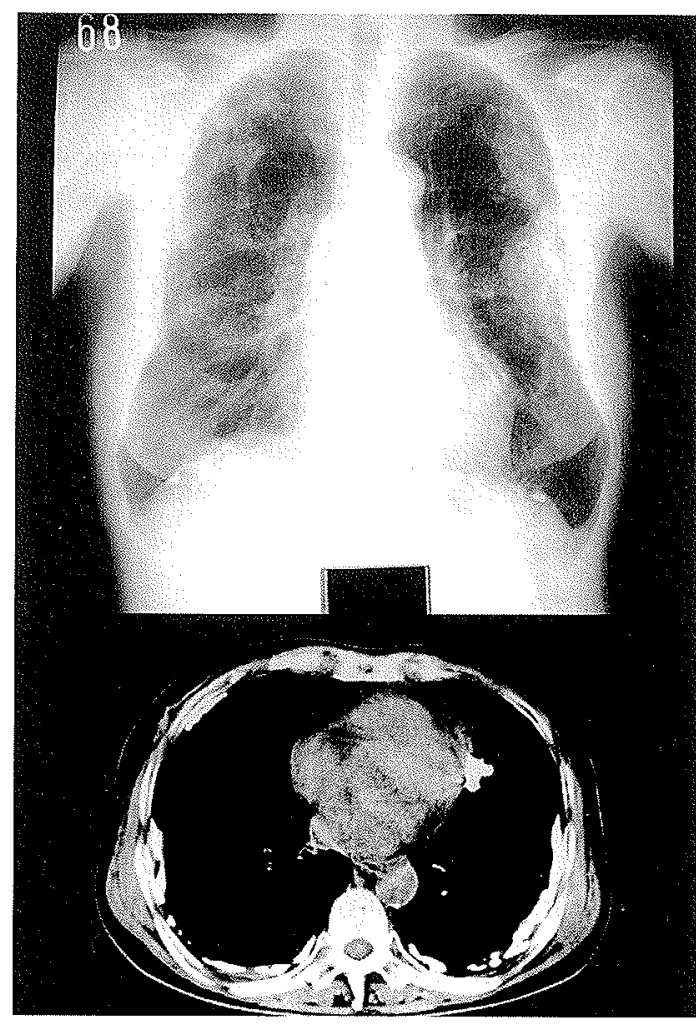

Figure 4. A 63-year-old woman with no occupational exposure to asbestos. Her chest-ray film reveals bilateral calcified plaques of the costal pleura, diaphragm, and pericardium. 
more neighboring towns had a higher prevalence of pleural plaques than the more distant towns had. Matsubase, however, showed the highest figures. A total of 89 former employees of asbestos mines and factories was traced and interviewed. Among these persons, pleural plaques were found in $64(72 \%)$, a figure which however constituted only $6.8 \%$ of all the cases of plaques found in the area. Some of these former workers had severe radiological pleural changes (including changes of the visceral pleura), but many had only minor pleural changes.

No difference in the severity of pleural plaques was detected in the chest roentgenograms between the persons with (figure 3) or without (figure 4) an occupational history of asbestos exposure.

The age-adjusted mortality rate (per 100000 ) for lung cancer for both the men and the women in Matsubase (24.8) was lower than in the Kumamoto prefecture (32.8) (table 3). No case of malignant mesothelioma has been reported in Matsubase during the past 17 years.

The concentration of asbestos fibers in the air around the closed asbestos mill was lower than in Kumamoto city (table 4). Thus, at present, there is no environmental asbestos pollution in the area.

\section{Discussion}

In the historical records of Matsubase (15), the operating of asbestos mines and factories has been documented from about 1883. Initially only a small amount of asbestos ore was mined, but, from 1935 to 1945 , several mines and factories were opened and actively operated. After World War II, 1 mine and 1 factory continued to operate at Niregi until about 1970. The asbestos mines were all open cast. The asbestos ore, once mined, was transported in carts to the factories. Then, the ore was crushed and refined into asbestos fibers. The high-quality fibers were mainly sold to factories in Osaka, Kobe, and Tokyo. Some of the low-grade ore was used in the production of fire-resistant panels and small cooking stoves. Thus asbestos dust was released into the environment for a period of approximately 80 years in this area.

The inhabitants were exposed directly from their occupation or indirectly from environmental pollution (16). The results of the asbestos ore analysis showed that the largest mine produced anthophyllite, while some of the small mines produced chrysotile and talc (17).

The history of asbestos exposure was often difficult to obtain, whether the person in question had worked in the factory or in the mine. Most inhabitants older than 60 years had forgotten their occupational careers during World War II since it usually involved only short-time
Table 3. Age-adjusted mortality rate from lung cancer for men and women combined in Matsubase and its surrounding areas between 1986 and 1990.

\begin{tabular}{lrcc}
\hline Area & $\begin{array}{c}\text { Population } \\
(\mathrm{N})\end{array}$ & $\begin{array}{c}\text { Deaths } \\
(\mathrm{N})\end{array}$ & $\begin{array}{c}\text { Age-adjusted } \\
\text { mortality rate }\end{array}$ \\
\hline Matsubase & 22817 & 34 & 24.8 \\
Shiranui & 9964 & 19 & 37.1 \\
Uto & 33656 & 68 & 42.9 \\
Jounan & 17370 & 26 & 29.5 \\
Toyono & 5334 & 14 & 45.7 \\
Ogawa & 13991 & 24 & 31.5 \\
Kumamoto Prefecture & 1845448 & 2953 & 33.9 \\
\hline
\end{tabular}

a The age-adjusted mortality rate (per 100000 ) from lung cancer was calculated on the basis of the mortality statistics between 1986 and 1990 and the census of 1990 . The total Japanese population in 1990 was used as reference.

Table 4. Airborne asbestos levels in Matsubase and Kumamoto as of November 1990.

\begin{tabular}{lc}
\hline & Air samples (fibers/l) \\
\cline { 2 - 2 } Matsubase & \\
Abandoned factory (Nigeri) & 0.3 \\
Near a former factory & 0.27 \\
Matsubase & \\
Point 1 & 0.21 \\
Point 2 & 0.18 \\
Point 3 & 0.19 \\
Point 4 & 0.16 \\
Reference area & \\
Residential area (Kumamoto) & 0.51 \\
Commercial area (Kumamoto) & 1.72 \\
Beside a highway (Kumamoto) & 2.44 \\
Rural district & 0.26 \\
Hilly village & 0.15 \\
\hline
\end{tabular}

employment in the beginning of their worklives. Most of the workers had been engaged in the asbestos mines or mills for less than 3 years, and only a few persons had more than 10 years' employment.

It was also found that many women had worked in the factories for a short duration. This finding might explain why there were no differences in the severity of pleural plaques between the persons with or without occupational asbestos exposure.

At least 938 inhabitants with pleural plaques are currently living in Matsubase. When those living in the surrounding towns are added, the total number of persons with pleural plaques is more than 1000 .

However, the mortality rate from lung cancer, which is the most common of asbestos-related malignancies, is not higher in Matsubase than in the other regions of the Kumamoto prefecture (table 3), nor has there been any evidence of malignant mesothelioma, the most specific of the asbestos-related malignancies, during the last 17 years at the National Kumamoto Minami Hospital, which is the center for respiratory diseases servicing the Matsubase area. The fact that there is a high prevalence of 
pleural plaques but a low mortality rate from lung cancer and no evidence of mesothelioma is in accordance with the characteristics of anthophyllite asbestos exposure.

In Japan, small amounts of chrysotile are mined, and large amounts of asbestos (chrysotile, crocidolite, and amosite) are imported from foreign countries (18). As far as we know, anthophyllite has not been mined in any other places in Japan outside the Matsubase area.

Endemic pleural plaques due to anthophyllite exposure has been reported from Finland (4), where there is a high prevalence of people with extensive pleural calcification due to nonoccupational exposure. In this Finnish area, anthophyllite can be found in rocks, which have been used by the inhabitants for building saunas and the like, and this occurrence may explain the high prevalence of plaques there. However, since it was shown that asbestos fibers can spread up to $27 \mathrm{~km}$ from mines (19), pollution from the mining activities may have been of considerable importance, similar to what happened in Matsubase. As in the Matsubase area, there had been a few asbestos mines and factories, and the ore was also transported in open carts from the mills to the factory, making it possible for the fibers to scatter. Thus the high prevalence rate of pleural plaques in this Finnish area may to some degree have the same explanation as in Matsubase (ie, widespread environmental pollution due to occupational activities).

As a result of the works done by Sleggs (20) and Wagner et al (21), there is now no doubt that there is a direct causal relationship between asbestos exposure and the development of mesothelioma. However, many studies have shown that the different types of mineral fibers vary in their potential to cause mesothelioma. Erionite, a fibrous zeolite (ie, a nonasbestos fiber) and crocidolite asbestos are the most potent in this respect, while anthophyllite fibers seem to carry only a small risk (22). Thus anthophyllite is an interesting mineral, causing a high prevalence of calcified pleural plaques but only rarely mesotheliomas (23).

In agreement with an earlier study from Finland (24), diffuse pleural thickening due to asbestos exposure was rare also in the Matsubase area.

Currently, in Matsubase, the mines are closed and covered by soil, and there is no asbestos pollution from these mines. Medical follow-up of the people living in the area has continued since 1990.

\section{Acknowledgments}

We would like to express our thanks to Dr Yoshizumi Sera and Dr Kunihiko Yokoyama for their kind advice, and Dr Gunnar Hillerdal for his valuable comments.

\section{References}

1. Frost J, Georg J, Miller P. Asbestosis with pleural calcification among insulation workers. Dan Med Bull 1956;3:2024.

2. Anton HC. Multiple pleural plaques. Br J Radiol 1965;40:685-90.

3. Hillerdal G. Pleural plaques in a health survey material: frequency, development, and exposure to asbestos. Scand J Respir Dis 1978;59:257—63.

4. Kiviluoto R. Pleural calcification as a roentgenologic sign of non-occupational endemic anthophyllite-asbestosis. Acta Radiol 1960;194 suppl:1—65.

5. Burilkov T, Michailova L. Asbestos content in the soil and endemic pleural asbestosis. Environ Res 1970;3:443-51.

6. Rous V, Studeny J. Etiology of pleural plaques. Thorax 1970;25:270-84.

7. Neuberger M, Grundorfer W, Haider M, Konigshofer R, Muller HW, Raber A, et al. Endemic pleural plaques and environmental factors. Zentralbl Bakteriol Hyg I Abt Orig B 1978;67:391-404.

8. Constantopoulos SH, Saratzis NA, Kontagiannis D, Karantanas A, Goudevenos JA, Katsiotis P. Tremolite whitewashing and pleural calcifications. Chest 1987;92:709-12.

9. MacMonnochie K, Simonato L, Mavrides P, Christofides P, Mitha R, Griffiths DM, et al. Mesothelioma in Cyprus: the role of tremolite. Thorax 1987;42:342-7.

10. Rey F, Boutin C, Steinbauer J, Viallat JR. Alessandroni P, Jutisz P, et al. Environmental pleural plaques in an asbestos exposed population of northeast Corsica. Eur Respir J 1993;6:978-82.

11. Hiraoka T, Kiyota S, Shima K, Kinuwaki E, Kimura T, Fukuda $\mathrm{K}$, et al. Analysis of pleural plaque found at lung cancer screening examination [in Japanese]. Jpn J Thorac Dis 1990;28:1566-72.

12. Hiraoka T, Hiro $Y$, Kohyama N, Morinaga $\mathrm{K}$. Anthophyllite exposure and endemic pleural plaques in Japan. In: International Labour Organisation (ILO). Proceedings of the eighth international conference on occupational lung diseases, Prague. Geneva: ILO, 1992:248-53.

13. Askergren A, Szamosi A. Relation between radiological pleuropulmonary changes, clinical history and weight index of construction workers. Scand J Work Environ Health 1978;4:179-83.

14. Air Quality Bureau. Japan environmental agency: manual of asbestos emission in the general environment [in Japanese]. Tokyo: Gyousei, 1990.

15. Hayashida N. Matsubase town's history [in Japanese]. Matsubase: Matsubase Town Government, 1979:23 \& 361-2.

16. Hiraoka T, Ando M, Shima K, Kinuwaki E, et al. Epidemiologic survey of pleural plaques among inhabitants of Matsubase exposed to asbestos [in Japanese]. Jpn J Thorac Dis 1996;34:385-91.

17. Kohyama N, Hiraoka T. Asbestos from an old mine in Kumamoto Prefecture and asbestos in the lungs of inhabitants around the mine from where a high incidence of pleural plaques was found [in Japanese]. Jpn J Ind Health 1994;36 suppl 397.

18. Morinaga K, Kohyama N, Yokoyama K, Yasui I, Hara I, Sasaki M, et al. Asbestos fiber content in the lungs of mesothelioma in Osaka, Japan. In: Bignon J, Peto J, Saracci R, editors. Non-occupational exposure to mineral fibers. Lyon: International Agency for Research on Cancer (IARC), 
1989:438-43. IARC scientific publications, no 90.

19. Raunio V. Occurrence of unusual pleural calcification in Finland: studies on atmospheric pollution caused by asbestos. Ann Med Int Finnae Suppl 1966;47:1—75.

20. Sleggs CA. Clinical aspects of asbestosis in the Northern Cape. In: Orenstein AJ, editor. Proceedings of the pneumoconiosis conference. London: J \& A Churchill Ltd, 1960:38390.

21. Wagner JC, Sleggs CA, Marchand P. Diffuse pleural mesothelioma and asbestos exposure in the Northwestern Cape Province. Br J Ind Med 1960;17:260—71.
22. Hillerdal G. Diffuse malignant mesothelioma 1983: review of 4710 published cases. Br J Dis Chest 1982;77:321 - 44 .

23. Meurman LO, Kiviluoto R, Hakama M. Mortality and morbidity among the working population of anthophyllite asbestos miners in Finland. Br J Ind Med 1974;31:105-12.

24. Hillerdal G, Zitting A, van Assendelft AHW, Kuusela T. Rarity of mineral fiber pleurisy among persons exposed to Finnish anthophyllite and with a low risk of mesothelioma. Thorax 1984;39:608-11.

Received for publication: 6 April 1998 